\title{
Application Study of CDIO Engineering Education Model in Civil Engineering Materials
}

\author{
Zhou Yanhua \\ Jiangxi University of Technology,Nanchang Key Laboratory of material and structure detection
}

\begin{abstract}
CDIO engineering education model is the latest achievement of engineering education reform in recent years. And it is established with 4 years of exploration and research by the multinational research organization, including Massachusetts Institute of Technology and other 3 universities. It is a new, efficient engineering education concept that allows students to take initiative, practical and organic relative way among courses to learn engineering course. This paper focuses on how to conduct CDIO mode construction according to CDIO syllabus, from three aspects of "Civil Engineering Materials" course, including the theoretical knowledge, practical skills system, interpersonal skills system, and discusses the supporting measures in the implementation process of the "Civil Engineering Materials" curriculum CDIO mode. Practice shows CDIO model is popular with students and has strong vitality.
\end{abstract}

Keywords: CDIO model; civil engineering materials; hierarchical and modular; reform

\section{I.INTRODUCTION}

CDIO engineering education model is the latest achievement in recent years of international engineering education reform. And it is established with 4 years of exploration and research by the multinational research organization, including Massachusetts Institute of Technology and other 3 universities. The established new, highly efficient engineering education concept has been gradually extended in many international engineering education reforms. CDIO means Conceive, Design, Implement and Operate, and it takes the life cycle from product development to product running as the carrier, to enable students to take the way of initiative, practice and organic links between courses to study engineering.

After several rounds of teaching summary, the author made a full range of multimedia courseware for civil engineering materials course, and collected related experimental videos and combined a variety of teaching methods with the utilization of writing on the blackboard, multimedia, video recording in teaching, and strived to achieve the best teaching effect, for example, some experiments are time-consuming and it's impossible to arrange students to do the experiments. Through video recording, multimedia animation and other means, students can learn while raising their interests, combined with the visual experience, it's easier to have students grasp the theory knowledge, resulting in more effective teaching. Students can fully grasp the basic technical properties of the materials.

\section{II.DESIGN OF CIVIL ENGINEERING MATERIALS COURSE}

\section{CDIO MODE}

The CDIO syllabus (abridged version) targeting ability training is shown in Table 1, from content design of the table, we can see that CDIO syllabus implements three kinds of organic binding capacity of the structure: Firstly, it's a kind of the theoretical level knowledge, including the knowledge system that individual engineer must master, consisting by basic sciences, core engineering base and advanced engineering base; the second is the ability system of practice level, including the reasoning and problem-solving skills, the ability of test and knowledge discovery, systems thinking abilities that the project engineer must have, as well as the ability to design, implement and operate (CDIO) engineering products / systems in business and social environment; Thirdly, interpersonal skills system, including teamwork and communication skills, foreign language communication skills. For these three ability structures, civil engineering materials exploration includes the following three aspects. 
TABLE I. TCDIO SYLLABUS TARGETING ABILITY TRAINING (ABRIDGED VERSION)

\begin{tabular}{|c|c|}
\hline 4 types of abilities & 17 groups of abilities \\
\hline 1st type: technical expertise and inferential capability & $\begin{array}{l}\text { 1. Basic knowledge } \\
\text { 2. Basic knowledge of core engineering } \\
\text { 3. Basic knowledge of high-level engineering }\end{array}$ \\
\hline 2nd: individual vocational skills and professional ethics & $\begin{array}{l}\text { 1.Engineering reasoning and problem solving } \\
\text { 2.To explore knowledge in experiments } \\
\text { 3. Systems thinking } \\
\text { 4. Personal skills and attitudes } \\
\text { 5. Vocational skills and attitudes }\end{array}$ \\
\hline $\begin{array}{l}\text { 3rd type: interpersonal skills: teamwork and } \\
\text { communication }\end{array}$ & $\begin{array}{l}\text { 1. Team work } \\
\text { 2. Communication } \\
\text { 3. Foreign language communication }\end{array}$ \\
\hline $\begin{array}{l}\text { 4th: Conception, design, implementation and operation } \\
\text { ( CDIO) and other various systems in business and society }\end{array}$ & $\begin{array}{l}\text { 1. External and social environment } \\
\text { 2. Enterprise and business environment } \\
\text { 3. Conception and engineering system } \\
\text { 4. Design } \\
\text { 5. Implementation } \\
\text { 6. Operation }\end{array}$ \\
\hline
\end{tabular}

\section{BASIC TECHNICAL KNOWLEDGE OF CIVIL ENGINEERING}

\section{MATERIALS AND REASONING ABILITY}

Emphasize students' practical reasoning ability according to the CDIO syllabus and on the basis of mastering basic theoretical knowledge. The author made following teaching trials within his own teaching practice:

(1) Teaching effectiveness is enhanced by using the "open experiment cognition" in the classroom. For some materials performance test that cannot arrange students to do experiments, let the students watch and learn by laboratory instruments show and field operations of laboratory personnel, and experimental resources will be consumed less and students will also have more interests and impressions than only watching experimental videos, achieving more obvious teaching effect. They can understand the basic technical properties of the material through initial awareness.

(2) Strengthen communication with the experiment teacher and change the gappy status of current experimental and theoretical teaching arrangement, effectively avoiding the problem of poor synchronization of theoretical study and experimental study, mastering the learning characteristics of students.
(3) Timely present the design problem of experiment material and let them design material by themselves to deepen the grasp of basic knowledge.

(4) Real-time change of the teaching place, that is, the teaching place will be changed according to different teaching contents. For example: the study of "concrete and workability" section uses the laboratory on-site teaching method, through experimental demonstration of concrete workability, including the meanings, characteristics and experimental key points of "liquidity", "cohesion", "water retention" for emotional awareness, so that our students can really appreciate the learning process of " practice first, theory second, practice again", learning effect being improved significantly.

\section{REFORM TEACHING PROCESSES}

(1) Emphasize traditional teaching process. Students just start to learn the specialized courses, with little actual contact, lacking of perception for a variety of materials, so teachers should play the role of pathfinder to teach knowledge and solve questions for students, opening the door to numerous civil engineering material world; and the content of "Civil Engineering Materials" curriculum covers a wide range, the logical relationship among the contents is imprecise, and the teachers have to carry out 
key elements to explain in detail, connecting each individual section together to form an organic whole.

(2) Make full use of advanced teaching methods. "Civil Engineering Materials" curriculum involves many engineering materials and products, production processes, structure, and construction and so on, and most of them cannot be moved to the classroom, even if the teachers teach very hard, and sometimes it is difficult to mobilize the interest of students. So advanced teaching methods must be used. With multimedia teaching methods, teachers have to spend a lot of time and effort to make good multimedia courseware, however, through in-kind pictures, animations and videos, a lot of available information can be provided to students intuitively. The creation of situations can greatly improve credit hours efficiency, mobilizing the students' interest and enthusiasm.

(3) Actively open the second classes. The second class is not limited to the classroom, but expanding to laboratory, construction sites and even the building materials market. While learning in the classroom students can have a certain understanding for civil engineering materials, but there is a certain distance of theory and practice. Teachers can take the students to the laboratory, site and building materials market and let students observe, explore and compare the actual materials. Teachers choose some key, representative, attractive layout issues to students, guiding students to find information, make courseware and presentations, classroom lectures led by students, but the time cannot be long.

\section{V.CONCLUSION}

In summary, based on CDIO philosophy, the author conducts a series of reforms based on the courses on civil engineering materials, from basic intellectual capacity, personal practical skills enhancement, experimental attitude training, experiment teamwork culture and other aspects to carry out teaching practice and achieved good teaching results.
1. Based on CDIO philosophy, civil engineering material capacity training outline is established, from the basic knowledge and reasoning ability, practical skills and personal attitudes culture experiments, experimental team building and collaboration ability, conceptual design and implementation abilities respectively to conduct teaching practice and summary.

2. Establishing new teaching model and capacity in line with the 12 evaluation criteria that CDIO syllabus following, improve the students' enthusiasm for learning, and enhance the students' ability to deal with practical problems.

\section{REFERENCES}

[1]Engineering C E. CV2003 - Civil Engineering Materials[J]. Dictionary Geotechnical Engineering/wörterbuch Geotechnik, 1998, 20(18):4987-4990.

[2]Coster M, Chermant J L. Image analysis and mathematical morphology for civil engineering materials[J]. Cement \& Concrete Composites, 2001, 23(2-3):133-151.

[3] Ong J B, You Z, Mills-Beale J, et al. A Wireless, Passive Embedded Sensor for Real-Time Monitoring of Water Content in Civil Engineering Materials[J]. IEEE Sensors Journal, 2009, 8(12):2053-2058.

[4]Wyk A J V, Swart P L, Chtcherbakov A A. Coaxial/cylindrical transition line for broadband permittivity measurement of civil engineering materials[J]. Measurement Science \& Technology, 2006, volume 17(8):2241-2246(6)

[5]Engineering C E. CL371/CV2003 - Civil Engineering Materials[J]. Dictionary Geotechnical Engineering/wörterbuch Geotechnik, 2008, 20(18):4987-4990

[6]Wang H, Yang Y, Guo W. Reform on design experiment teaching of cement mortar of civil engineering materials[J]. Journal of Architectural Education in Institutions of Higher Learning, 2014.

[7]Wen Y, Han D M. Problem-based learning in open experiment teaching of civil engineering materials[J]. Journal of Architectural Education in Institutions of Higher Learning, 2010.

[8]Vimer C, Asce M, Yu S, et al. Probing $\mathrm{pH}$ Levels in Civil Engineering Materials[J]. Journal of Materials in Civil Engineering, 2009, 21(2):51-57

[9]Masad E, Sivakumar K. Advances in the Characterization and Modeling of Civil Engineering Materials Using Imaging Techniques[J]. Journal of Computing in Civil Engineering, 2004, 18(1):1-1

[10]Ming-Zhe A N, Zi-Ruo Y U, Zhang H. Cultivation of students' practical ability in civil engineering materials teaching $[\mathrm{J}]$. Journal of Architectural Education in Institutions of Higher Learning, 2010.

[11]YANG Yi bo a, Liu Q Z A, Shi X Z A, et al. Study on Interactive Courseware of Civil Engineering Materials Experiment[J]. Journal of Architectural Education in Institutions of Higher Learning, 2008.

[12]Monchau J P, Marchetti M, Ibos L, et al. Infrared Emissivity Measurements of Building and Civil Engineering Materials: A New Device for Measuring Emissivity[J]. International Journal of Thermophysics, 2014, 35(9-10):1817-1831. 